\title{
Effects of salt water on the ballistic protective performance of bullet- resistant body armour
}

Dodd, S. ${ }^{1}$, Malbon, C. ${ }^{1}$, Critchley R. ${ }^{1}$, Lankester, C. ${ }^{1}$, O’Rourke, S. ${ }^{2}$, Corke, T. ${ }^{3}$, Carr, D.J. ${ }^{1,4}$

${ }^{1}$ Centre for Defence Engineering, Cranfeld University, Defence Academy of the UK, Shrivenham, SN6 7ES, UK.

${ }^{2}$ Home Office Centre for Applied Science and Technology, Sandridge, St Albans, AL4 9HQ, UK.

${ }^{3}$ Ministry of Defence Police Headquarters, Wethersfield, Essex, CM7 4EQ, UK

${ }^{4}$ current address: Defence and Security Accelerator, Porton Down, Salisbury, Wiltshire, SP4 OJQ, UK.

Corresponding author:

Dr R. Critchley, Centre for Defence Engineering, Cranfeld University, Defence Academy of the UK, Shrivenham, SN6 7ES, UK. Email: r.critchley@cranfield.ac.uk 


\title{
Effects of salt water on the ballistic protective performance of bullet- resistant body armour
}

\begin{abstract}
Bullet resistant body armour is used by law enforcement agencies and military personnel worldwide, often in inclement weather. Some fibre types used in body armour perform poorly when wet resulting in a reduced level of protection; this is why most body armour protective elements are water-repellent treated and / or protected by a water-resistant cover. Some of the users operate in the maritime environment. The effect of salt water on body armour performance has not been previously reported. In this work the effect of soaking body armour in salt water and exposing body armour for up to ten soaking and drying cycles in salt water was investigated. The effectiveness of the water-resistant cover was investigated by considering three cover conditions i) intact, ii) cut and iii) removed. Wet armour was heavier and provided significantly less protection from 9mm Luger FMJ ammunition when compared to not-conditioned armour irrespective of cover condition. The presence of a cover (intact or cut) resulted in heavier armours and poorer protection as the water was less able to drain out of the armour. A degradation in performance of armours exposed to soaking and drying cycles was noted, but this was similar across all regimes considered (one, three, five and ten cycles) and not as great as for wet armours.
\end{abstract}

\section{Keywords}

Burden; Backface signature; Behind armour blunt trauma; Perforation; Degradation

\section{Introduction}

Bullet resistant body armour is used by law enforcement agencies and military personnel worldwide. Body armours typically consist of two major elements i) soft armour which provides protection from targeted threats including fragmentation, sharp-weapons and pistol ammunition (depending on intended end-user) and ii) hard body armour plates 
(dependant on threat these are either ceramic faced / composite backed or $100 \%$ composite) that provide protection from high velocity rifle ammunition (Lewis et al., 2017). Protection is 'measured' by considering whether or not the ammunition of interest perforates the armour (i.e. passes through the armour into the body) and by measuring the backface signature (BFS) which is the amount of deformation of the rear of the armour due to a non-perforating event (Croft and Longhurst, 2007). BFS cannot be directly correlated to behind armour blunt trauma (BABT), but standard test methods provide a maximum allowable BFS (Croft and Longhurst, 2007). BABT injuries that body armour wearers suffer are typically bruises to the skin and to some underlying organs, and broken ribs (Carr et al., 2016). Soft armours are made using fabrics containing para-aramid (e.g. Kevlar ${ }^{\circledR}$, Twaron $^{\circledR}$ ) or ultra-high molecular weight polyethylene (UHMWPE e.g. Dyneema ${ }^{\circledR}$, Spectra ${ }^{\circledR}$ ) fibres and provide protection from a range of projectiles dependent upon construction (Lewis et al., 2017).

The properties of para-aramid fibres are affected by moisture; UHMWPE fibre as less susceptible (Li et al., 2015). The ballistic protective performance of wet para-aramid fabrics is reportedly up to $40 \%$ lower than dry para-aramid fabrics (Laible, 1980; Gibb, 2005). To minimise the risk of moisture affecting the protective performance of para-aramid fabrics used in body armour they are often water repellent treated and/or enclosed in water resistant covers, which are typically made from polyvinyl chloride (PVC). However, with everyday usage the covers can become damaged and potentially split, allowing the ingress of moisture in to the ballistic protective element. In addition, if the body armour becomes submerged in water (for example the wearer falls into a body of water) it is possible that water will permeate through the PVC cover resulting in the para-aramid fabric becoming saturated.

Within the UK, there are a number of in-shore and off-shore police marine units who have a responsibility for patrolling the waterways around the UK, including providing specialist firearms support during operations (Ministry of Defence, 2018).These patrols are often conducted using Rigid Hulled Inflatable Boats (RHIBs) which expose the occupants to the effect of salt water spray, especially in rough sea conditions; potentially resulting in the body armour they are wearing becoming wet. There is always a risk of the RIB occupants entering the water. How salt water affects the ballistic performance of body armour is not 
known. Although the body armour is dried between patrols, the effect of regular soakings with salt water and drying has also not been previously studied. Laundering (washing and drying cycles) can affect the ballistic protective performance of fabrics (Helliker et al., 2014).

The salinity of sea water varies worldwide between $31 \mathrm{~g} / \mathrm{L}$ and $38 \mathrm{~g} / \mathrm{L}$ with $\mathrm{pH}$ varying between 7.5 and 8.4; the mean salinity of sea water at Harwich over a 12-month period was $34.48 \mathrm{~g} / \mathrm{L}$ (Centre for Environment Fisheries and Aquacultre, 2018).

This paper investigates the effect of soaking and soaking and drying cycles in saline water typical of UK sea water on the ballistic performance of a typical UK Police Authorised Firearms Officer (AFO) para-aramid body armour.

\section{Method}

Plastic containers were filled with a salt water solution of $35 \mathrm{~g} / \mathrm{L}$ salinity. The water was monitored using an Extech ${ }^{\circledR}$ RF20 portable salinity refractometer and $\mathrm{pH}$ paper to ensure it was between $34-35 \mathrm{~g} / \mathrm{L}$ and a $\mathrm{pH}$ of 8 throughout the soaking regimes investigated (see below).

Body armours were selected that were certified to the UK Home Office standard HG2 / KR2 protection level that is typically worn by AFOs (Croft and Longhurst, 2007). The armours contained front and rear panels in an outer cover; each panel contained a protective pack with a water-resistant cover. The protective packs of the armours consisted of a HG2 element with a KR2 element located at the rear ${ }^{1}$. The body armours had been previously issued to officers and were beyond their shelf-life expectancy, however all panels were inspected prior to testing for signs of damage and only those classified with no visible damage were used for this work. The panels were prepared in pairs for testing in one of three 'cover' conditions:

1. water-resistant cover intact,

2. water-resistant cover cut on the edges with $50 \mathrm{~mm}$ slits at 6 locations (Figure 1 ) and

3. water-resistant cover completely removed.

\footnotetext{
${ }^{1} \mathrm{HG} 2=$ handgun protection level 2; KR2 = knife protection level 2
} 


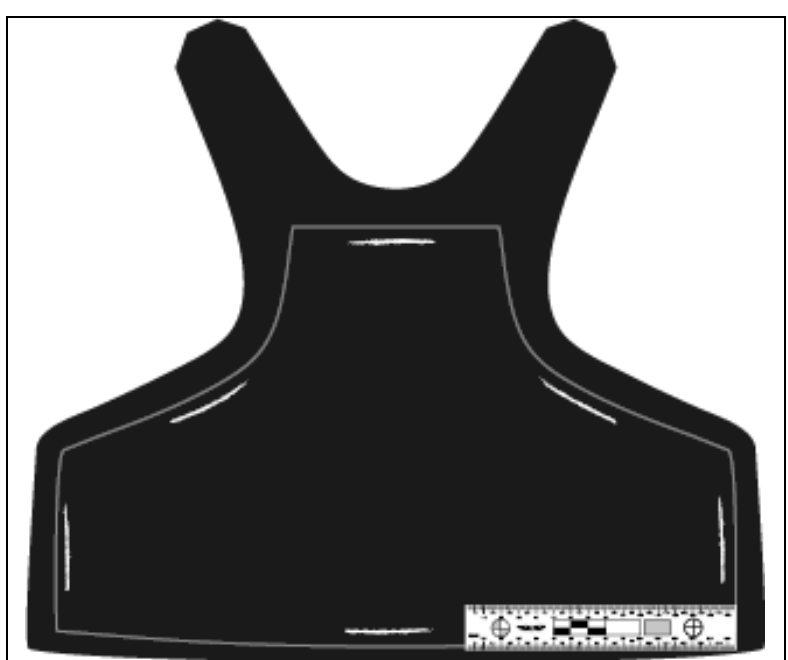

Figure 1 Location of cuts in body armour covers

To provide baseline data, two test panels were tested as-received with covers on and two tested as-received with the covers removed (i.e. test panels were not subjected to an 'exposure' regime). For each cover condition described above, two test panels were subjected to one, three, five or ten cycles of 3-hours soaking and 45-hours drying. Test panels were dried vertically at $20 \pm 3{ }^{\circ} \mathrm{C}$ with the final drying process timed to enable the armour panels to be tested within 30-minutes of completion of the final 45-hours drying period. An additional set of two test panels were prepared for each cover condition and subjected to ballistic testing 'wet' by soaking in salt water for 3-hours and then drying vertically for 5-minutes before the first test shot was taken. The test schedule is presented in Table 1.

Table 1 Test schedule ( $\boldsymbol{n}=\mathbf{2}$ for each cover condition / exposure combination)

\begin{tabular}{|l|l|}
\hline cover & exposure regime \\
\hline Intact & as-received \\
\hline removed & as-received \\
\hline Intact & soaked (3-hours) and dried (45-hours) for one cycle \\
\hline Intact & soaked (3-hours) and dried (45-hours) for three cycles \\
\hline Intact & soaked (3-hours) and dried (45-hours) for five cycles \\
\hline Intact & soaked (3-hours) and dried (45-hours) for ten cycles \\
\hline Cut & soaked (3-hours) and dried (45-hours) for one cycle \\
\hline
\end{tabular}




\begin{tabular}{|l|l|}
\hline Cut & soaked (3-hours) and dried (45-hours) for three cycles \\
\hline Cut & soaked (3-hours) and dried (45-hours) for five cycles \\
\hline Cut & soaked (3-hours) and dried (45-hours) for ten cycles \\
\hline removed & soaked (3-hours) and dried (45-hours) for one cycle \\
\hline removed & soaked (3-hours) and dried (45-hours) for three cycles \\
\hline removed & soaked (3-hours) and dried (45-hours) for five cycles \\
\hline removed & soaked (3-hours) and dried (45-hours) for ten cycles \\
\hline Intact & soaked (3-hours) and dried (5-minutes) \\
\hline Cut & soaked (3-hours) and dried (5-minutes) \\
\hline removed & soaked (3-hours) and dried (5-minutes) \\
\hline
\end{tabular}

Before and after the defined soaking and drying or soaking regimes, the test panels were weighed to two decimal places (i.e. $0.01 \mathrm{~g}$ ) to determine any change in mass.

The test panels were marked with shot locations one to five in accordance with the HOSDB 2007 standard and mounted on trays of calibrated Roma Plastilina No 1 (Croft and Longhurst, 2007). Each test panel was shot five times from a distance of $5 \mathrm{~m}$ with $9 \mathrm{~mm}$ FMJ Luger DM11A1B2 bullets using a proof housing fitted with a $580 \mathrm{~mm}$ barrel (1 in 11 twist). The impact velocity of each shot was recorded using a Weible W-700 Doppler radar. Between each shot the test panel was checked for perforation by the bullet and the backface signature (BFS) recorded by measuring the depth of the indentation in the Plastilina using a calibrated depth gauge. The test panel was smoothed between shots and repositioned on the tray.

\section{Results}

\section{Effect of conditioning on mass of panel}

Mean mass data for pairs of front and back test panels across all variables are presented in Table 2. All exposed test panels were heavier than not-exposed test panels. Wet test panels were the heaviest for all cover conditions. For all soaking and drying regimes except one cycle, test panels with the cover removed had the smallest increase in mass; for test panels exposed for one soaking and drying cycle the intact cover set had the smallest increase in mass, but this was very similar to the increase in mass for panels exposed to one soaking and drying cycle with the cover removed ( $12 \%$ and $14 \%$ respectively). Considering the mean 
mass across all test panels exposed to soaking and drying regimes, similar changes in mass were observed after exposure for one, five and ten soaking and drying cycles (15\%, $14 \%$, $15 \%$ respectively); a heavier change in mean mass was observed after exposure for three soaking and drying cycles (25\%). Test panels that had their water-resistant covers intact or cut were heavier irrespective of having been exposed to a soaking and drying or soaking regime.

Table 2 Mean mass data (\%) for test panels ( $n=2$ per variable combination)

\begin{tabular}{|l|l|c|}
\hline Cover & exposure & mean change in mass (\%) \\
\hline Intact & not-conditioned & 0 \\
\hline removed & not-conditioned & 0 \\
\hline Intact & one cycle & 12 \\
\hline Cut & one cycle & 19 \\
\hline removed & one cycle & 14 \\
\hline Intact & three cycles & 30 \\
\hline Cut & three cycles & 24 \\
\hline removed & three cycles & 20 \\
\hline Intact & five cycles & 18 \\
\hline Cut & five cycles & 17 \\
\hline removed & five cycles & 8 \\
\hline Intact & ten cycles & 21 \\
\hline Cut & ten cycles & 16 \\
\hline removed & ten cycles & 8 \\
\hline Intact & wet & 70 \\
\hline Cut & wet & 61 \\
\hline removed & wet & 25 \\
\hline
\end{tabular}

\section{Ballistic testing}

Mean impact velocity for the ammunition used was $415 \mathrm{~m} / \mathrm{s}(\mathrm{SD}=4 \mathrm{~m} / \mathrm{s})$. One of the 170 impacts resulted in a perforation of the complete test panel i.e. both the HG2 and KR2 portions (cover removed, exposed to three soaking and drying cycles, $412 \mathrm{~m} / \mathrm{s}$ ). All ammunition expanded on impact with the test panels irrespective of other variables considered.

The ballistic protective performance of the test panels was assessed by considering the proportion of shots that perforated the HG2 packs ( $n=2$ packs, $n=5$ shots per pack 
across all variables) i.e. whether the bullet was retained in the HG2 pack or in the KR2 pack located towards the rear of the test panel. Summary data across the two variables of cover condition and exposure regime are given in Table 3. No shot perforated the HG2 packs of the not-exposed test panels irrespective of the cover being present or not. However, the majority of shots on wet test panels perforated the HG2 packs (mean $=87 \%$ ); further analysis suggested that presence of the water-resistant cover reduced this degradation, $70 \%$ of shots perforated the protected HG2 packs compared to $100 \%$ of shots when the cover was removed. A large degradation in ballistic protective performance was also noted for test panels that had been exposed to one or three cycles of soaking and drying in saline water when the cover was removed. However, this degradation was reduced as the number of exposure cycles increased. Cycled test panels with covers intact typically provided a higher level of protection than test panels with the covers damaged or removed. The exception to this was for three soaking and drying cycles with the cover intact.

Table 3 Percentage of shots that perforated HG2 packs ( $n=10$ per variable condition)

\begin{tabular}{|l|l|c|}
\hline Cover & exposure & \% of shots that perforated HG2 packs \\
\hline Intact & not-conditioned & 0 \\
\hline removed & not-conditioned & 0 \\
\hline Intact & one cycle & 0 \\
\hline Cut & one cycle & 10 \\
\hline removed & one cycle & 100 \\
\hline Intact & three cycles & 50 \\
\hline Cut & three cycles & 0 \\
\hline removed & three cycles & $100 *$ \\
\hline Intact & five cycles & 0 \\
\hline Cut & five cycles & 0 \\
\hline removed & five cycles & 10 \\
\hline Intact & ten cycles & 0 \\
\hline Cut & ten cycles & 0 \\
\hline removed & ten cycles & 30 \\
\hline Intact & Wet & 70 \\
\hline Cut & Wet & 90 \\
\hline removed & Wet & 100 \\
\hline
\end{tabular}

*one bullet perforated the test panel 
The BFS values were measured for each shot and summary statistics are provided in Table 4. Data variability (expressed as CV) ranged from $5 \%$ to $33 \%$ with no obvious trend due to the variables considered (Table 4). Fourteen of 169 shots (one perforation) resulted in a BFS of greater than $25 \mathrm{~mm}$ (the maximum allowable in the standard the armours were designed against). Of these, 11 shots were on wet armours; i.e. $37 \%$ of shots on wet armour resulted in a BFS greater than that allowed in the standard. In comparison no shots onto the not-exposed armours resulted in a BFS greater than $25 \mathrm{~mm}$. Considering the mean BFS across each variable, only one exposure regime resulted in a mean BFS greater than $25 \mathrm{~mm}$, that was for armours with intact covers shot while wet (5 out of 10 shots resulted in a BFS greater than $25 \mathrm{~mm}$ ). Considering the two variables of cover condition and exposure regime in greater detail, the lowest mean BFS was observed for not-exposed test panels, the highest for wet test panels. With respect to increasing numbers of soaking and drying cycles similar values for mean BFS were observed for one, three and five cycles irrespective of cover condition with a slight decrease for ten cycles $(20 \mathrm{~mm}, 19 \mathrm{~mm}, 19 \mathrm{~mm}$ and $17 \mathrm{~mm}$ respectively). The condition of the water-resistant cover did not appear to affect the measured BFS in test panels exposed to soaking and drying regimes.

Table 4 Summary statistics for backface signature ( $n=10$ per variable condition)

\begin{tabular}{|l|l|c|c|c|}
\hline Cover & Condition & mean (mm) & SD (mm) & CV (\%) \\
\hline Intact & not-conditioned & 14 & 4 & 29 \\
\hline removed & not-conditioned & 18 & 2 & 11 \\
\hline Intact & one cycle & 19 & 1 & 5 \\
\hline Cut & one cycle & 21 & 2 & 10 \\
\hline removed & one cycle & 18 & 4 & 22 \\
\hline Intact & three cycles & 19 & 4 & 21 \\
\hline Cut & three cycles & 17 & 4 & 24 \\
\hline removed & three cycles & $19 *$ & 3 & 16 \\
\hline Intact & five cycles & 18 & 3 & 17 \\
\hline Cut & five cycles & 20 & 2 & 10 \\
\hline removed & five cycles & 19 & 4 & 21 \\
\hline Intact & ten cycles & 21 & 2 & 10 \\
\hline Cut & ten cycles & 17 & 4 & 24 \\
\hline removed & ten cycles & 12 & 4 & 33 \\
\hline Intact & Wet & 26 & 2 & 8 \\
\hline Cut & Wet & 23 & 5 & 22 \\
\hline removed & Wet & 24 & 3 & 13 \\
\hline
\end{tabular}


*one bullet perforated the test panel

\section{Discussion}

There are several points that require discussion i) mass of test panels, ii) perforation of test panels and iii) effect on backface signature.

The wet test panels were the heaviest as expected. Water ingress occurred into the individual fabric layers. Wet test panels with the covers intact or slit were much heavier (up to $70 \%$ ) than all other test panels presumably due to the water being trapped in the covers and not being able to drain out; this is further evidenced by the wet test panels with covers removed having a lower mass $(25 \%)$ than the other wet test panels. Other work has demonstrated large increases in mass when various fabrics and garments are wet e.g. (Laing et al., 2010; Crow and Osczevski, 1998; Laing et al., 2008). That mass of the test panels increased after soaking and drying exposure cycles in a saline solution was also expected and is likely due to salt crystallising and being trapped within the fabric and panel structure during the drying process. Residual moisture may have also remained trapped in the fabric packs. It was noticeable that test panels with intact covers exposed for three soaking and drying cycles had a higher mass (30\%) than other test panels exposed to soaking and drying cycles with their covers intact (12\%, $18 \%$ and $21 \%)$; this may be due to degradation of the seams of the covers before testing resulting in a greater ingress of moisture which became trapped during the drying phase. Excluding the test panels exposed for three soaking and drying cycles, an upward trend in mass was observed suggesting increased amount of trapped crystalline salt in the panels with an increasing number of soaking and drying cycles.

Previously published research (for fresh not saline water) suggested that a degradation in performance of up to $40 \%$ occurred for wet compared to dry ballistic protective fabrics (Laible, 1980; Gibb, 2005). Degradation in protection was observed in the current work for wet test panels, although at a higher level; this might be due to the different projectiles used. The previous work used non-deforming $1.1 \mathrm{~g}$ steel fragment simulating projectiles at similar impact velocities to the current work which used $9 \mathrm{~mm}$ Luger FMJ ammunition that expanded on impact with the test panels. The 1.1g FSPs will be more penetrative due to the concentration of the kinetic energy over a smaller strike face. Higher 
levels of degradation were also observed for specimens with covers removed that had been exposed to soaking and drying cycles; this suggested that the covers provide some protection from the degradative effects observed. It is noticeable that the higher level of HG2 element perforation observed for test panels with intact covers exposed for three soaking and drying cycles correlated with the increased mass for these panels further suggesting trapped moisture due to seam disruption (Tables 2 and 3 ).

That a higher number of shots on wet panels compared to dry panels resulted in a BFS greater than that allowed in the standard was expected; similar results have been observed in test laboratories worldwide for decades, but are rarely reported openly. Whether such increases in BFS would lead to more severe BABT is difficult to comment on, however, given an increase in BFS by as much as $25 \%$ it does seem likely that a more injurious event would occur. When considering test panels that had been exposed to cycles of soaking and drying, a slight increase in BFS compared to not-exposed panels was observed, but this was still within the limit of $25 \mathrm{~mm}$ in the standard giving confidence in the protection offered by armours that had been exposed in such a way.

\section{Limitations}

This work was conducted using one type of body armour and one type of ammunition at a given velocity. The results are not necessarily transferable to other armour systems, ammunition and exposure conditions. However, the work suggests that these other situations should be considered.

\section{Conclusions}

Wet armours provide less protection than dry armours. If the armour gets wet ensuring that is has completely dried is important as this work suggested that residual moisture can affect ballistic protective performance with respect to an increased likelihood of more severe BABT. Armour exposed to soaking and drying cycles (up to ten) in saline water was affected with respect to the protection levels offered, but the results suggested that a satisfactory level of protection would still be provided. 


\section{Acknowledgements}

This paper was written from Lt Dodd's MSc thesis in Explosive Ordnance Engineering and was supported by HQ Ministry of Defence Police and the Home Office Centre for Applied Science and Technology. The authors acknowledge the assistance of Ms C. O'Keeffe (formally of Cranfield University, now at the University of Bristol).

\section{References}

Carr DJ, Horsfall I and Malbon C. (2016) Is behind armour blunt trauma a real threat to users of body armour? A systematic review. Journal of the Royal Army Medical Corps 162: 8-11.

Centre for Environment Fisheries and Aquacultre. (2018) Sea water and salinity trends. Available at: https//www.cefas.co.uk/.

Croft J and Longhurst D. (2007) HOSDB Body Armour Standards for UK Police. Part 2: Ballistic Resistance Publication No. 39/07/B. Sandridge, St Albans: Home Office Scientific Development Branch.

Crow RM and Osczevski RJ. (1998) Interaction of water with fabrics. Textile Research Journal 68: $280-288$.

Gibb RM. (2005) The effect of water of the performance of ballistic textiles. Cranfield University.

Helliker M, Carr DJ, Lankester C, et al. (2014) Effect of domestic laundering on the fragment protective performance of fabrics used in personal protection. Textile Research Journal 84: 1298-1306.

Laible RC. (1980) Ballistic materials and penetration mechanics: Elsevier Publishing Company. 
Laing RM, Gore SE, Wilson CA, et al. (2010) Standard test methods adapted to better simulate fabrics in use. Textile Research Journal 80: 1138-1150.

Laing RM, Sims ST, Wilson CA, et al. (2008) Differences in wearer response to garments for outdoor activity. Ergonomics 51: 492-510.

Lewis EA, Malbon C, Breeze J, et al. (2017) Personal armour used by UK Armed Forces and UK Police Forces. In: Breeze J, Penn-Barwell J, Keene D, et al. (eds) Ballistic Trauma. 4th ed. London, UK: Springer International Publishing.

Li Y, Li C, Zheng J, et al. (2015) Effects of water on the ballistic performance of para-aramid fabrics: three different projectiles. Textile Research Journal 86: 1372-1384.

Ministry of Defence. (2018) Ministry of Defence Police. Available at:

http://www.mod.police.uk/specialist/marine.html. 